\title{
Sharing Anxiety is in the Driver's Seat: Analyzing User Acceptance of Dynamic Ridepooling and Its Implications for Shared Autonomous Mobility
}

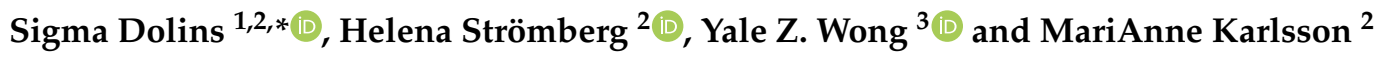 \\ 1 Mobility and Systems, RISE Research Institutes of Sweden, Lindholmspiren 3A, 41756 Göteborg, Sweden \\ 2 Design \& Human Factors, Chalmers University of Technology, 41296 Göteborg, Sweden; \\ helena.stromberg@chalmers.se (H.S.); mak@chalmers.se (M.K.) \\ 3 Institute of Transport \& Logistics Studies, University of Sydney Business School, \\ Darlington, NSW 2006, Australia; yale@drtransportation.org \\ * Correspondence: sigma.dolins@ri.se
}

check for updates

Citation: Dolins, S.; Strömberg, H.; Wong, Y.Z.; Karlsson, M. Sharing Anxiety is in the Driver's Seat: Analyzing User Acceptance of Dynamic Ridepooling and Its Implications for Shared Autonomous Mobility. Sustainability 2021, 13, 7828. https://doi.org/10.3390/su13147828

Academic Editors: Margareta Friman, Lars Olsson and Hugo Guyader

Received: 31 May 2021

Accepted: 30 June 2021

Published: 13 July 2021

Publisher's Note: MDPI stays neutral with regard to jurisdictional claims in published maps and institutional affiliations.

Copyright: (c) 2021 by the authors. Licensee MDPI, Basel, Switzerland. This article is an open access article distributed under the terms and conditions of the Creative Commons Attribution (CC BY) license (https:// creativecommons.org/licenses/by/ $4.0 /)$.

\begin{abstract}
As connected, electric, and autonomous vehicle (AV) services are developed for cities, the research is conclusive that the use of these services must be shared to achieve maximum efficiency. Yet, few agencies have prioritised designing an AV system that focuses on dynamic ridepooling, and there remains a gap in the understanding of what makes people willing to share their rides. However, in 2017, the Australian transport authority Transport for New South Wales launched over a dozen trials for on-demand, shared public transport, including AVs. In this paper, we investigate the user willingness-to-share, based on experiences from one of these trials. Four focus groups (19 participants in total) were held in New South Wales with active users of either the trialled on-demand dynamic ridepooling service (Keoride) or commercial ridepooling (UberPool). Through thematic analysis of the focus group conversations, the cost, comfort, convenience, safety, community culture, and trust in authority emerged as factors that influenced the willingness-to-share. When presented with driverless scenarios, the focus group participants had significant concerns about the unknown behaviour of their co-passengers, revealing sharing anxiety as a significant barrier to the adoption of shared AVs. This paper identifies previously disregarded factors that influence the adoption of AVs and dynamic ridepooling and offers insights on how potential users' sharing anxiety can be mitigated.
\end{abstract}

Keywords: shared mobility; dynamic ridepooling; autonomous public transport; on-demand transport; shared autonomous vehicles

\section{Introduction}

Autonomous vehicles (AVs) have been presented by numerous manufacturers, transport agencies, and city planners as a technology that promises to radically transform cities. AVs are, for example, argued to enable denser urban development (particularly in land areas that are traditionally used for parking), reduce the overall congestion on the roadways, and reduce fuel consumption and $\mathrm{CO} 2$ emissions [1]. In addition, AVs are contended to improve the quality and productivity of the time spent in-vehicle, increase the safety and efficiency of the transportation system, and transform transportation into a utility available to anyone at anytime [2].

Other suggested benefits of AVs are that they could increase the mobility of commuters and user groups that do not have driver's licenses and, according to Becker and Axhausen [3] (p. 1294), "many who rely on public transport in remote areas, could be offered independent and individual transport solutions". While there are likely to be some negative impacts, such as increased energy consumption due to repositioning, these have been suggested as less significant and potentially mitigated if all future AVs are electric [4]. 
Nevertheless, even with a fully electrified fleet, numerous studies indicate that the potential of AVs cannot be fully realized except through their use as purveyors of shared, pooled rides. In operating fleets of shared AVs, there are potentially system-wide benefits; an increase in vehicle occupancy is expected to reduce the number of cars needed to meet the travel needs of a given population, which could lead to moderating congestion and unlocking beneficial changes in urban form, such as decreasing the real estate devoted to standing parking and enable healthier pedestrian-focused spaces in urban environments [5-10]. Essentially, the development of fully self-driving cars is believed to solve many of the barriers associated with shared vehicle systems from both the provider and user perspectives, making it possible to respond better to service demands [1].

However, without established concepts or a use culture about how to share the asset of a vehicle, Fraedrich et al. [11] point to the likelihood that individuals will expect to use $\mathrm{AVs}$ like they use their privately-owned cars today. AVs as a private household good, and not a shared product, could lead to significant problems. If people accept to use AVs as a private household good, there is also the potential for a significant decrease in public transit ridership; already transportation networking companies (such as Uber) and ridehailing (the use of an mobile phone app to book a taxi service on-demand) have had a controversial effect on public transit, with some studies showing that there was a net reduction in transit use after the introduction of ridehailing services [12,13]. In order for public transit not to be negatively impacted by AVs, they will need to be shared; or better yet, part of the public transport offering.

Without strong incentives for shared AVs (SAVs), single-occupancy, zero-occupancy, or privately owned AVs are at risk for increasing traffic congestion, encouraging urban sprawl, increasing energy consumption, and worsening socio-economic stratification at the personal level [14]. Therefore, it becomes crucial to examine the behaviours that would support "dynamic ridepooling": matching ride requests so that multiple groups of passengers can be booked to the same vehicle in an efficient and environmentally-sound manner. By understanding how to encourage the acceptance of dynamic ridepooling, it would become easier to introduce SAVs as a public good or service, such as part of the public transport system.

SAVs as public transport means that the individual person is burdened less with the financial needs of acquiring and maintaining personal transport or transport for family members, while still benefiting from door-to-door or nearly door-to-door convenience. SAVs as public transport could also mean safer transportation networks with fewer accidents and losses to the economy due to injury, property destruction, or death; these things contribute to the improved health and social well-being of citizens $[15,16]$. Nonetheless, any benefit of services based on shared AVs will only materialise if enough individuals are willing to adopt them. In our examination of previous work, we found that there was a knowledge gap in understanding the willingness-to-share dynamic ridepooling, and perhaps an overemphasis on investigating the technological acceptance of AVs.

Aim

The aim of the reported study was to contribute to more in-depth knowledge on factors impacting people's willingness-to-share mobility journeys and trips, especially in a shared autonomous public transport context. We, therefore, applied a qualitative approach to address the following questions:

- What factors (if any), beyond socio-economic factors, impact travellers' willingnessto-share on-demand services?

- What factors impact the willingness-to-share on-demand public transport?

- $\quad$ Are these the same factors or different ones?

- If the on-demand public transport vehicle is a shared AV, does the willingness-to-share the service of travellers change? 


\section{Related Work}

Designing AVs to be a shared, on-demand product is believed to be key to transitioning into the widespread adoption of autonomous mobility and associated social benefits. We reviewed previous research into the factors that impact the willingness-to-share for contemporary ridehailed services, which could indicate the future willingness-to-use for AVs. In particular, we were interested in work that could build towards the acceptance of SAVs as part of the public transport system.

According to Merat, Madigan, and Nordhoff [15] (p. 20), "there is potential for the mass-deployment of a new form of publicly available, electrically operated, 'driverless' vehicle for the urban environment, which can be adopted for sole or shared use and provide first mile/last mile transport". In other words, AV technology could force the evolution of a new form of travel that offers the convenience, flexibility, and comfort of a private vehicle with public accessibility and ownership: communally-owned, SAVs as public transport [1].

In order to understand people's willingness-to-share in human-driven, on-demand ridehailing services, a substantial number of studies have focused on socio-demographic determinants, such as age, gender, ethnicity, and income; it has, for example, been noticed that younger individuals are more likely to adopt pooled services than older individuals [17-19] and, further, that women are more positive than men [20-22]. Other studies have investigated relevant service attributes and found factors, such as travel time and cost $[23,24]$, as well as a distrust of others and concerns for security and privacy to be important determinants for travellers' decisions to share or not [25-27].

Prior research into the usage of AVs has been focused primarily on people's acceptance of the type of vehicle per se. A common theme has been user attitudes towards the technology, since it is widely believed that the adoption of AVs will be dependent on the individual perceptions of automated transport, and personal attitudes towards new forms of technology [28]. In addition, also in this context, many socio-economic factors been examined, such as gender, age, and household income [3], and literature reviews of AV studies concluded that AVs appear to be embraced by young people, highly educated people, higher-income people, and urbanites and, further, that more males and current vehicle owners with advanced driver assistance systems tend to be the most positive towards AVs $[15,29,30]$.

However, in order to understand user acceptance of shared AVs, and shared AVs in a public transport context, a range of other factors may arise. However, while there is plenty of work on the technological acceptance of AVs and willingness-to-pay or share in on-demand ridehailing, there appears to be considerably less work explicitly examining the merging of both: i.e., user willingness-to-share their space and their journey with others in a shared AV.

Typically, propositions rely either on extrapolating results from studies of public transport or of AVs or on different types of large surveys. An example of the former is Merat, Madigan and Nordhoff [31] who suggested that, in order to use AVs as public transport, the service must have the same or similar features and benefits that are offered by privately owned vehicles, for example being available at any time and being able to go anywhere. An example of the latter is Madigan et al. [32] who, based on an adaptation of the Unified Theory of Acceptance and Use of Technology model, found that factors, such as performance expectancy, hedonic motivation, and social influence, positively influenced people's intention to use automated road transport systems.

Other studies suggested that there is a need to expand the existing dataset with additional geographic diversity and variables to track the evolution of perceptions on shared automated vehicles, both temporally and spatially [33], indicating that there could be a cultural or community-based dimension. The MERGE [32] project was one of the few previous studies that took a qualitative approach. In this case, the result of focus group interviews showed that potential customers want to know that the new AV technology is safe; however, they are also concerned with the service design of a shared AV and what kind of processes are in place to protect passengers from both riders and vehicle failures. 
While previous studies have provided some insights into influencing factors, there is still limited knowledge about under what conditions users are willing to ridepool with others in SAVs. Preparing for that transition requires a more in-depth understanding of what may affect people's likelihood of using these services and their possible concerns [33].

\section{Methodology}

This study was performed as part of a larger, mixed methods project. The larger project assumes an international and multicultural perspective, and this study was carried out with the intention to perform qualitative data collection with (potential) users of shared autonomous public transport services in three countries:

- Australia, where the public transport authority of New South Wales has demonstrated high levels of innovation of both on-demand public transit and AV pilots and deployments;

- France, a global leader in developing some of the first AV shuttles on the market, with numerous deployments of on-demand public transit services and the location of some of the most challenging AV pilots; and

- $\quad$ Sweden, with a strong history of both institutional and public support for public transit, vehicle innovation, but a lack of commercial dynamic ridepooling services.

Each country has distinctly different mobility products and public opinions towards AVs and public transport $[3,34,35]$, and comparisons between the three should prove valuable to understanding measures for increasing the acceptance of shared, autonomous mobility. To understand what makes people more likely to share their rides with strangers (both with human-driven services from transportation network companies, as well as in a future AV context) requires employing qualitative methods to better understand the mixed emotional experience and underlying values that drive the usage of such mobility platforms [36].

\subsection{Focus Group}

This paper is concerned with initial qualitative data collection activities, which were completed in Australia from October 2019 to November 2019. Focus groups were chosen, as this is an acknowledged qualitative research technique that offers the researcher an opportunity to reach an insight that is otherwise difficult to obtain from other methods, such as a closed question survey. Participants are able to freely disclose their experiences, opinions, thoughts, and feelings without constraint, which was considered essential when discussing with potential users for a service that does not currently exist. According to Casey and Krueger, focus groups provide "a more natural environment than that of (the) individual interview because participants are influencing and influenced by others-just as they are in real life" [37] (p. 11); they can, thus, yield data that is not possible with other approaches, including one-to-one interviews.

Within Australia, the state of New South Wales (NSW) was selected for the focus groups because TfNSW has funded several on-demand public transport services, and AV demonstrations throughout the state, thus, giving credence to the claim that in 2019, it had the most innovative mobility service pilots in the country. At the time of the study, TfNSW had 17 active on-demand van or bus transport services (ODT), most of them pilots, as well as three AV pilots. However, when the study was carried out, two pilots were temporarily delayed and one was a demonstration in the Sydney Olympic Park area, which is a tourist destination and somewhat remote when events are not in season. The decision was made not to recruit users from these services as they were not considered representative of future use.

All the ODT trials were funded by TfNSW as part of a transport system innovation programme, demonstrating a willingness to innovate and test on-demand transport in metropolitan contexts as well as in regional and rural cases. The approach was unusual from other cities, municipalities or regional governments, even in other countries, in that the transport authority took a market-driven approach, where transport operators 
suggested and designed the initial pilot areas, and there has been significant involvement from local transport operators and technology providers as well as multinationals.

More specifically, the trials were financed via six-month contracts with the option to extend contracts after the initial trial period. The various trials were delivered through partnerships between the local transport operators and technology providers [38]. This includes transport operators, such as the Punchbowl Bus Company, ComfortDelGro, Community Transport Central Coast, Premier Motor Services, Transdev, BRIDJ, KeolisDowner, and Transit Systems Australia. The Northern Beaches trial was delivered through with KeolisDowner and GoGet, and the Keoride app was powered by Via, a software development company. TfNSW and KeolisDowner focused on recruitment for data collection with Keoride users, as well as general members of the public who use Uber or who live near to $\mathrm{AV}$ and ODT trials.

Four focus groups were conducted throughout Sydney and Newcastle, in New South Wales. There were two categories, with two focus groups in each:

- Experienced Users: people who were currently riding Keoride, a public transport, on-demand dynamic ridepooling service promoted by TfNSW and operated by KeolisDowner. Keoride launched in November 2017 and served the Northern Beaches and Macquarie Park areas at the time of the study.

- Potential Users: people who lived in an area where autonomous shuttle pilots or dynamic ridepooling was available, either from public transport or commercial actors. Most of their dynamic ridepooling experience was gained through using a commercial ridehailing product known as UberPool or Ola, ridehailing services that could be found in New South Wales. They were considered "potential" users because, although they did not use (or were often unaware of the existence of) Keoride, they were customers of similar services and had the potential to become users of an on-demand public transport service.

\subsection{Participants}

Focus groups are typically conducted with a small group of participants who are recruited based on certain criteria; Merton et al. [39] (p. 137) described the focus group size to ideally to be not so large "as to be unwieldy or to preclude adequate participation by most members nor should it be so small that it fails to provide substantially greater coverage than that of an interview with one individual". The participants were recruited to take part in two categories of focus groups: potential users (persons familiar with on-demand trips, i.e., users of dynamic ridepooling through commercial products) and experienced users (persons recruited from the public transport on-demand ridepooling service). This meant that all participants had some familiarity with digitally-enabled, on-demand ridehailing services: either the commercial ridepooling product UberPool or the public transport product Keoride.

The focus group participants came from four areas in New South Wales: Newcastle, Macquarie Park, Inner West, and Northern Beaches (the latter three are located in Sydney). More information specific to these neighborhoods and their characteristics can be found in Appendix B.

The Northern Beaches focus group was the smallest, at two persons, the Newcastle group involved five persons, and the Macquarie Park and Inner West groups each had six participants. There were a total of 19 participants, with 11 total participants in the Potential User category, and 8 total participants in the Experienced User category.

Experienced Users were recruited through the assistance of the public transit operator KeolisDowner; site selection was, thus, somewhat bound by the location of the experienced users to Northern Beaches and Macquarie Park. Potential Users were recruited through the online task managing service Airtasker and recruited in neighbourhoods near to university campuses, which tend to have a diverse population and access to public transport. All participants were reimbursed for their time in the form of a monetary incentive and food. 


\subsection{Data Collection}

The design of the focus group interview in terms of interview questions and flow were developed through two test focus groups. The final structure was a staged, consecutive, guided process that involved the following phases:

- Introduction: getting to know each other, discussing transportation.

- Present situation: how participants currently commute or travel.

- Foundational definition of Shared On-Demand Transport (video \#1).

- Current experiences with Shared On-Demand Transport and/or Commercial Dynamic Ridepooling.

- Direct appeal: how would you personally suggest increasing the acceptance of shared mobility?

- Definition of Future Service (video \#2).

- Views on sharing a ride in an AV service.

The questions posed focused on two important sharing aspects: aspects of space, by sitting in a vehicle where other passengers would also be sitting, and aspects of prioritization, where your overall travel time would be potentially impacted by the joined passengers.

The two videos (\#1 and \#2) were used as mediating tools (these videos can be found in Appendix A). The first video was promotional material from an existing Transport for New South Wales on-demand public transport service and was used in order to ensure all participants had a common understanding of how on-demand transportation worked. The second video was promotional material created by MOIA, the Volkswagen-backed shared ridehailing startup in Hamburg, Germany.

The MOIA service video was shown in order to give a similar foundation about the future definition of dynamic ridepooling, as well as raise expectations about potential vehicle designs and formats, by portraying a very high level of service and comfort not currently available in Australia. The goal was to see if these videos would impact the participants' views towards dynamic ridepooling positively. If participants were attracted to the vehicle features, that could be interpreted as evidence that service design and spatial features in the vehicle increase acceptance of shared public transport, and could be used to increase acceptance of shared autonomous public transport.

A moderator (the first author) guided the discussion in the chronological funnel, and one facilitator (the third author) assisted with the logistics of technology, arrivals, and food. All focus groups were audio recorded. Each session lasted approximately 90-100 min.

\subsection{Analysis}

To analyse the qualitative data from the focus group interviews, a combination of deductive and inductive analysis of themes was used. The audio recordings were transcribed in full and the transcriptions broken down into categories for conceptual analysis.

First, an initial list of categories, i.e., pre-defined codes, was generated based on the literature on dynamic ridepooling, ridehailing, carpooling, and similar shared mobility experiences. This initial list included codes, such as "cost", "safety", and "trust in public authority", and was developed by the first author. A second set of pre-defined codes was developed in dialogue between the first, second, and fourth authors based on previous research on sharing: these included, for example, "community", "family influence", and "in-car culture".

The codes were then used to label segments of interview data to depict the content of each segment. This labelling was done in Atlas.ti, a qualitative data analysis software (QDAS) tool, often used to support analyses of data gathered through interviews, focus groups, field notes, and open-ended survey questions. However, the codes were not sufficient to cover all the content of the focus group interviews. Thus, in a third step, further codes were developed using a more inductive approach. This final step resulted in codes, such as "value of private space" and "previous negative experiences".

To provide insight into which factors or issues were the most concerning for different users, the coded material was further examined to determine what themes had emerged, 
which were the most frequent throughout all four focus groups, and which ones were the most frequent in a particular focus group as well as the rationale behind them. In order to be able to identify what data was collected in which focus group, the coded segments were also labelled according to Table 1.

Table 1. This table describes the focus group participant nomenclature.

\begin{tabular}{cccc}
\hline Focus Group Category & Location & Gender & Participation \\
\hline Potential User (POT) & Newcastle (NC) & Male (M) & 1 \\
Potential User (POT) & Inner West (IW) & Female (W) & 2 \\
Experienced User (EXP) & Macquarie Park (MP) & Male (M) & 3 \\
Experienced User (POT) & Northern Beaches (NB) & Female (W) & 4 \\
Example Code: POT-NC-M1 & Potential User Group & Newcastle & First Male \\
\hline
\end{tabular}

The result of the qualitative analysis is presented by using illustrative quotes with a label, (see Table 1). The first author did the initial coding of the transcripts. In order to check the consistency and coherence of the coding, the second and third authors received an excerpt of the transcripts with instructions for the coding, including the list of codes and their definitions. The initial overall agreement between the first author's and the second and fourth authors' classifications was $71 \%$; further discussions between these authors on specific sections of the transcripts was able to produce consensus.

\section{Results}

The focus group interviews confirmed four previously identified factors influencing the travellers' willingness to use ridepooling or on-demand transport services: cost, comfort, convenience (and time, which was a consistent element in describing the importance of cost or convenience), and safety. These results are presented here as reconfirmed factors, followed by the revealed factors.

\subsection{Reconfirmed Factors}

\subsubsection{Cost}

Cost is one of the primary factors in any decision between transportation choices [3,22,40]. Both potential and experienced users said that they were willing to support dynamic ridepooling services or on-demand transport services, even if prices were higher than typical public transport, so long as this service offered the convenience of a comfortable space, better sanitation (this was of some concern pre-COVID, as the research took place in November 2019; however, it became much more prominent in later focus groups that took place in 2020. That data is analysed separately in a future article), and flexible pick-ups, which they felt traditional public transport buses did not provide. However, this higher cost they were willing to pay had a boundary, in the form of being understood as cheaper than a traditional taxi.

Experienced users also mentioned that expensive parking made it difficult to maintain a private vehicle, so they opted to use on-demand transport services because the offered more comfort compared with traditional public transport but at cheaper rates than commercial services.

EXP-MP-M2: "I find that people's biggest surprise is, they can't believe it's only the same price as a bus. People assume it's going to be expensive, Uber priced at least. So I think that's probably a big barrier to folks. There's nothing that says where's cheapest, that it's cheaper than parking."

Potential Users from Newcastle offered a unique perspective on the subject of pricing; one participant explained that he prefers to arrange rides with friends and family members so that they would directly benefit from his pay, as opposed to supporting a company or corporation with which he is not connected. The group saw this form of personal social 
circle sharing not only as cost-efficient but also environmental-friendly and economically beneficial to the local economy, as opposed to paying, e.g., Uber or another outside entity.

\subsubsection{Comfort}

Potential Users (people who used commercial ridehailing as well as public transport) tended to have a more negative view of the comfort or amenities offered by public transport, compared to the Experienced Users who were recruited from on-demand public transport pilots. Participants discussed how the form factor impacted their views of comfort and safety as well as how the presence of other riders could disturb them.

POT-IW-M3: "No one likes the dirty seats on the buses or on the trains."

POT-IW-F2: "Mine [my concern] is some of the fools, the people, the randoms riding them, are unlikable. Really unlikable."

However, some users saw using public transport or on-demand ridehailing as a moment to disconnect from others and use for their own private ends.

EXP-NB-M1: "I multitask...that's why I like public transport because I can sit, I can do something. It's sort of my downtime, and I'm a full-time student and full-time working, it's my time to chill out and listen to music, or watch some TV on my phone, just sort of chill."

While both Potential Users and Experienced Users expressed anxiety about using shared, driverless mobility services, the nature of their anxiety seemed to differ. In the development of the focus group discussion, the MOIA service video served the role of grounding all of the participants' understandings of what a future on-demand service may look like. The video displayed a van specifically designed for shared rides between strangers, with separated seating, high head clearance, USB-ports, and a special screen display for the route. All of the participants were shown this video, and asked for their reaction: "What do you think about this vehicle and this service?"

When the participants were shown the video of high-end, specialized vans used for on-demand transport, Potential Users were the most positively affected by the video. They found the depicted service extremely appealing and said it would motivate them to use on-demand transport. They liked the attention to detail and generally luxurious feel of the service, comparing the MOIA service very favourably to their negative experiences with Uber or public transit, and indicated that, if MOIA were to begin in Sydney, they would be interested in using such a service.

POT-NC-F2: "That ticked all my boxes."

POT-NC-F3: "Personal space, plug in your laptop."

POT-NC-F1: "Charge your phone."

POT-NC-F2 "The comfort. They look luxurious, a big step up from a normal bus or public transport."

POT-IW-F3 "Yeah! Running between meetings. I've been on the phone all day. It would be awesome if I could whack it on in between transit, you know and charge my phone. That'd be amazing."

Other Potential Users mentioned that the consistency in physical format and features could help even vulnerable or physically-challenged riders to be more comfortable inside of the ride.

POT-NC-F3: "People, especially those in the spectrum, need that predictability and consistency, so having those kinds of social cues help us support them to use things like this. Otherwise there is that level of anxiety, it's not consistent, 'I don't know what to expect', and that's overwhelming for a lot of people."

Conversely, the Experienced Users who had been recruited from Keoride and had been using Kia Carnival, Mercedes Sprinter, or Toyota Rav models, were substantially 
more neutral than the potential user groups. Although these are conventional vans, mostly featuring bench seats and few other amenities, the Experienced Users did not feel like the MOIA service was a particularly compelling offer. Experienced Users believed the existing on-demand transport service was already a significant improvement over other forms of public transport and felt satisfied with the vehicles used in the fleet. Their biggest concerns were not with increasing the comfort offer of the vehicles that Keoride used but with improving other details of the service offering, such as more accurate pick-up and drop-off times.

\subsubsection{Convenience}

Another factor that presented itself in all groups was the importance of convenience.

EXP-NB-M1: "The pure beauty of Keoride is that it takes you to your home, so you're there, you don't have to go walking ten minutes or whatever up the hill, you're actually going home to your door, that's the best part, you know you're going to get to your door, at whatever time it says, in a safe environment..."

Several participants mentioned how on-demand ridehailing and dynamic ridepooling had increased their productivity because it freed them from the burden of driving themselves.

EXP-MP-M2: "I use Keoride solely for work commute because I explained earlier on that the ride from my place is very challenging for public transport and I found that Keoride gave me a very fast and convenient way to get to the work."

There were also concerns about the time a journey would take when talking about experiences with ridehailing. Specifically, dynamic ridepooling services were seen to not be able to provide the best time efficiency, as pick-up and drop-off times could vary.

POT-NC-F1: "If it was punctual and ran on time, that would be my biggest thing. Like, if I was driving, I would use it rather than having to pay for parking...it would need to be like efficient that you're not sitting somewhere waiting for 20 min after they said they'd be there."

From the Experienced User groups, there was a belief that the on-demand service was less useful when riders had time constraints on their journeys (a stronger limiter in the Keoride service than compared to the service used by participants in the potential user focus group, UberPool), which highlighted that, for certain trip journeys, the user flexibility and willingness-to-pay was dependent on their time constraints. They also expressed doubt that on-demand public transport could have the kind of fleet supply offered by commercial ridehailing.

EXP-MP-M2: "I don't think going to having no car and exclusively using Keoride, would ever be an option. I don't think there could ever be enough of them working 24/7 that we could do everything."

\subsubsection{Safety}

Safety was frequently discussed, chiefly as a concern about the behaviour of other passengers in either public transport or ridehailing settings. Potential user groups mentioned that there is no accountability in traditional taxi or ridehailing services.

POT-IW-F2: "We're still waiting for a taxi [Uber]. It transited through Strathfield. You don't get your fare back. The taxi goes 'Oh yeah, sorry.' He cancelled the fare and I just did, 'oh, no good'. No, not a good feeling. And that's why I've gone to a degree off Uber and onto Ola [competitor in commercial ridehailing], in the hope that maybe there might be some accountability, because the behaviour's appalling."

There was a collective notion among three of the four focus groups that the safety of women (in particular women who travel alone) needed to be addressed in commercial ridehailing and dynamic ridepooling, ranging from sharing personal space with unknown people to having to provide personal information to the services. 
POT-IW-F2: "Ridesharing is excellent [sarcasm]. . the whole UberPool, where you just pick up whoever. . [noise of unhappiness]."

POT-IW-F1: "Or they [other riders]. . call themselves something different [false identification in-app].... Like there's so many ways around that. I think I would be reluctant giving that type of information over. For me, it'd be more about, if anything goes wrong, Uber or the company responsible is going to release that information to the relevant authorities.

First Author: "So it's not that you want to have access to it, but you want to know that someone does."

POT-IW-F1: "Yeah, exactly. If I knew that there was safety and there were foolproof methods, no one's going to do anything bad if they know that their information is going to get leaked... Um, but I mean you do have to think about this, you do have to think about this a lot as a woman. So it's more knowing what's going to be done with that information. If you do ride with a creep, essentially."

Several participants expressed comparatively higher trust with public transportation than with ridehailing, partly because the physical format of most public transport (trains and buses) is larger, allowing for riders to move away from (perceived) dangerous elements or people but also since it offers a sense of collective responsibility in times of crisis.

POT-NC-F1: "For me, it, the safety concerns, would be worse on a train, because it's limited. It would be harder to get off in an emergency."

POT-NC-M1: "It would be the opposite for me. Say that, the guy giving me crap, he's at the front of the bus, I have to go past him to get off the bus. But on a train, I don't have to go by that guy. I know there are exits everywhere, doors down that way and everything."

Interestingly, safety concerns and issues with disruptive behaviour were completely absent from the conversations with Experienced Users from Macquarie Park, a community that is made up primarily of highly-skilled suburban commuters.

\subsection{Revealed Factors}

Where the focus groups began to diverge from the findings reported in literature or revealed deeper concerns and intentions came with the concepts of community (or common culture) and the importance of the driver as an authority figure.

\subsubsection{Community}

Most of the participants shared the view that public transportation and dynamic ridepooling services either instilled a sense of community or relied on an existing sense of community; they all agreed that the nature of the interactions within the vehicle were relationship-based.

First Author: "What about other people in the Keoride, do you share a lot?

EXP-NB-M1: "Yeah. So, there seems to be a lot of people. Like I know, you and I can always, have a chat, if we ever share. It's good. It's like a nice sort of community-oriented thing."

POT-IW-F3: "There is a social element to it. Finding something in common with the other people, whether it's a purpose or an interest. And for maybe the urgency as well."

POT-NC-FP3: "More important than the luxury part for me is that set social expectation, we know when I get on it the vehicle will leave, the bus will leave when it leaves, and they have the little screen to tell you when you'll be leaving or arriving."

It appeared that community-level differences affected how people gauged safety in public transportation. Three of the groups were from relatively homogenous areas. The Macquarie Park focus group, in particular, had the most homogenous ridership and displayed the lowest levels of safety concern, whereas the focus group from the most diverse neighborhood, Inner West, displayed the strongest fear of strangers and the lowest levels of trust in authority. 
In the Experienced User groups, since the population of riders was generally smaller and they had grown to rely on on-demand services for their daily commute, they felt that there was a new-but-becoming-the-norm expectation of behaviour within the vehicle. This was likely due to the fact that the same people had a much higher chance of encountering the same other passengers more frequently when using the on-demand service (Keoride) versus Potential Users, who would take Uber or other ridehailing services.

Experienced Users further explained that there is a "non-talking" culture inside of the vehicles, which some participants appreciated, given that they used the on-demand transport service for commuting. Participants in the experienced focus group from Northern Beaches agreed that not talking in public transport was a cultural norm, and one that was observed in many places around Sydney.

EXP-NB-F2: "My kids used to tell me to stop talking to people. I'm quite happy to start talking to people, but my daughter would be like 'no mum, you've got to stop doing that.' It's a cultural thing. In South America, in the Caribbean, or beyond Europe, other places, it's more open. It's truly a Western society and culture that people want their space. They have a bubble. You have to have that forever around you."

There was a strong connection in the focus groups between rider and driver, one that extended to their perception of public transport as well. Participants from the experienced focus groups mentioned much more positive interactions with their drivers. For example, respondents from Macquarie Park attributed a large part of their satisfaction with the ondemand transport service to its drivers; they described the drivers to be friendly, helpful, and polite. One respondent in the Northern Beaches group explained that the on-demand transport service offered a sense of familiarity, since the drivers were extremely friendly and remembered details about the passengers that made them feel seen and appreciated.

EXP-NB-M1: "But when it's a Keoride, you know the driver is right there. You know they, the vehicles, have been cleaned properly. You know that the vehicle is well maintained and the drivers really care about the cars. The drivers really care, and they're really just genuine people. All of them I've found are really nice, happy to have a chat. With bus drivers, I don't feel that way."

\subsubsection{Driver's Role}

As described earlier, the MOIA service video served the role of grounding the participants' understanding of what a future on-demand service may look like. After some discussion about their reactions to the MOIA video, the groups were asked: "How would you feel if you had access to this service, exactly as you've seen it, except that the vehicle is self-driving or autonomous?" Previous work on people's responses to the idea of self-driving vehicles identified fear or discomfort regarding the technology. However in this study, even with participants who expressed relatively low levels of fear of strangers, their fears seemed to increase when considering a future shared mobility service with the absence of a driver. The participants displayed emotional attachment to the drivers, not as purveyors of navigation services, but as an authority figure in the vehicle in the case of an emergency as well as a social representative of the community or service.

POT-IW-FP3: "So say for example, when I'm talking about a car, the car is automated, the person who makes the car is a variable, how to face it in terms of adversity? But when I'm the traveller and I'm just a traveller, it's not my work to know what the car should do and what the car shouldn't. I would panic, because I have no one out there to talk to and what should I do if I met with an emergency?"

POT-IW-FP1: "You can never get rid of that though. Like that's, that's the fear. At the moment they, the drivers see something weird going down and he goes 'right, you get out, you're impacting the safety of my ride, my other riders.'"

Potential User groups were concerned about their personal safety, what the process for reporting incidents would be like, and who would be the authority figure in a driverless vehicle. However, the two Potential User focus groups took place in very different commu- 
nities, Inner West and Newcastle. Inner West is an extremely diverse district of Sydney, and, in this focus group, there were low levels of trust in authority entities, in both the service operators and the transit agency, Transport for New South Wales. The other Potential focus group, in Newcastle, was from a less dense and more homogenous area of New South Wales. Their fears were different than the Inner West group, and less centred around personal safety; Novocastrians were more open to the idea of trying a shared, driverless vehicle but were still hesitant about trusting the technology or the service provider.

POT-IW-F2: "Yeah and I think as well the thing that's come out is that, you know, a lot of us like riding up front with drivers, you know one, there's the safety thing of having a driver there, but it is social. This is quite a social country, you know that you remove that, that's just another element in which we've taken, we've replaced a human with a screen or we've replaced a human with phaser technology. I wouldn't like that, you know. I might be in a shitty mood and not want to talk to a driver one day, but other times I do want to talk."

Previous research into the technological acceptance of AVs has uncovered levels of hesitancy and trepidation when it comes to driverless technology focused around the readiness and safety of the navigation and control. This did surface in our focus groups.

POT-NC-F2: "I'd give it a go..."

POT-NC-F1: "The robots are gonna be..."

POT-NC-F3: "I think there would be a lot more technical issues with a robot."

POT-NC-F2: "Easier to hack and stuff?"

POT-NC-F3: "I don't know, more breakdowns, I guess... . because they are more, wired, I don't know."

POT-NC-M1: "Like, if it can't get a signal, would it just stop where it is? Would it cause more accidents?"

Yet, the majority of the conversations centred not on technological concerns but on an anxiety that was based on a fear of strangers and the potential authority vacuum a driverless vehicle presented.

POT-NC-FP4: "It's not so much for me, the technology side of things. I'm quite comfortable with that. Um for me, if I was going to get on and other people get on the bus, and we tell the people we work with that 'if you have any problems you can talk to the bus driver', that level of human element, you can have all the buzzwords in the world, but to make sure people or even myself using it, but looking it as a service where we would want our people to use, reassuring them about the bus driver. . like my Pop, he's 93, he still catches the bus. And he, I don't think it's an age thing, but also if something did happen, who would he speak to...? There's a certain level of trust placed in the bus driver, there's an expectation they would be there to help, or do something."

Participants in both experienced and potential user groups said that in shared rides, they had felt uncomfortable with other passengers and the close proximity required by the vehicle designs. At the same time, it seemed that, in the groups from relatively homogenous communities (i.e., Macquarie Park, Newcastle), there was more comfort in riding with strangers than participants from more diverse areas (i.e., Northern Beaches and Inner West).

POT-IW-FP3: "And also your safety will be an even bigger issue. You're now travelling with randoms, with five people and nobody in charge of it."

POT-IW-FP1":"That's true, that's true. That would be different if I'm the only person and there's a remote driving the car or it's just been automatic. But if there are five people and if anything goes wrong, who's in charge? Who's charged for that?"

The importance of the drivers in a ridehailing service was significant in the experienced focus groups, where they felt attachment to the drivers as individuals and felt the drivers' role was to make their journey more pleasant and comfortable. When asked about dynamic ridepooling or on-demand transport in an autonomous vehicle, however, the experienced 
participants' reactions ranged from nervousness about possible misbehaviour of the other passengers, to being open to using shared AV services in the future-as long as certain processes were put in place and the technology had been tested.

EXP-MP-F3: "There has to be some sort of override or something. At any point or, I mean at the end of the day you'd probably have your app and there should be some sort of something where you can click like emergency or pause or break or help or something, there needs to be something where you can contact something if someone, if something goes wrong."

EXP-MP-F4: "So I suppose there's a security factor that they could be getting that you and the other person are the only people in there. There is no third person like the driver to make you feel a little bit more secure. If it was sort of..."

EXP-MP-M1:"If there was someone in charge?"

EXP-MP-F4: "Right."

EXP-MP-M1: "The question though is do you feel different using that? Do you feel like a Metro train is very different to an autonomous vehicle?"

EXP-MP-F4:"... I don't think I could answer that."

\subsection{Summary of Findings}

All of the participants had, at some point in their recent lives, used on-demand ridepooling services because they were cheaper than traditional taxis, provided a greater degree of flexibility, or a more comfortable experience. Safety was a more complex issue, with groups from relatively homogenous communities (Macquarie Park and Newcastle) indicating that they were more willing to use dynamic ridepooling or on-demand transport compared with participants from more diverse areas (such as Inner West).

However, the enthusiasm for dynamic ridepooling and on-demand transport dropped significantly in all four focus groups when presented with a scenario of using such services with a driverless vehicle. This revealed an unwillingness-to-share that extended beyond concerns over autonomous driving technology but rather indicating that human drivers were seen as a source of authority, a provider of safety or security, and a provider of personalization of service.

A clear difference emerged between the Potential Users and the Experienced Users. For Potential Users, whose experiences with commercial ridehailing were not consistent and undermined their confidence in the service providers, the vehicle amenities and comfort were extremely attractive and motivating factors for their willingness to use on-demand transport or share rides.

Conversely, those in the Experienced User groups felt confidence in the service, partly due to the fact that it was branded by a public transit authority, partly because of the comparatively higher quality of customer service they received from professional drivers, which contributed to the on-demand transport service, Keoride, offering a consistency of behaviour and expectations within the vehicle. The Experienced Users revealed a sense of community, or herd behaviour, given that they felt the other riders were similar to themselves and behaved according to (unspoken) expectations of politeness and safety. All these things combined meant that the vehicle itself-including the interior format or amenities-was not a motivating factor for these experienced users.

\section{Discussion}

Three themes emerged across all of the focus groups, independent of the type of service discussed: cheaper trips, better comfort, and increased convenience were qualities that appeared to motivate the use of shared mobility services. These factors have also been previously identified in other studies $[1,16,22,24-26,32]$ and were seen as motivating factors for using on-demand ridehailing, including dynamic ridepooling. Yet, there existed a demotivating factor, something that significantly dampened the enthusiasm for dynamic 
ridepooling, particularly in the context of autonomous and driverless vehicles: we call this 'sharing anxiety'.

Sharing anxiety, or this unwillingness-to-share, appeared to be the result of a complex relationship between several concerns:

- $\quad$ the overall impact on the journey time and quality;

- $\quad$ concerns about safety;

- concerns about personal space within the shared vehicle (sharing a public space with strangers); and

- $\quad$ trust in authority, such as a service operator or transit agency (the transit agency being a government authority).

How strongly sharing anxiety manifested was particular to each individual's experiences with public transport or commercial ridehailing and their perspectives or views about their community and local government authorities.

\subsection{Community (or Herd Behaviour)}

The social aspect of sharing and whether it was perceived positively or negatively, appeared differently between the Potential and Experienced Users, possibly due to expectations regarding behaviour and stemming from the belief that others using the service were similar to themselves or not. Potential Users, who were familiar with commercial ridehailing, felt less safe, comfortable, or trusting of other passengers or drivers, which was construed as a lack of community atmosphere or connection. They also expressed distrust or satisfaction with the customer service from the commercial providers, indicating low trust in the commercial authority. Experienced Users, however, felt the on-demand public transport service delivered on its promise, and that other riders understood the premise of the service, thus, creating the perception of a community of like-minded riders. What could explain this difference?

One possible explanation for why Potential Users felt less comfortable with sharing, comes from their first experiences with commercial, on-demand ridepooling. Previous commercial actors, including Uber or Didi Chuxing, introduced their shared ride services in large city areas, with the lure of high availability and cheap prices. While this attracted riders to the system, it also meant these transportation network companies had little control over the standards of service offered to users, creating an environment where there was a lack of community and inconsistent expectations. Participants in both types of groups felt that public transport was not always convenient or comfortable; however, the Experienced Users of on-demand public transport felt the vehicles and service offerings were a significant improvement over public buses as well as over commercial dynamic ridepooling.

Proof of this high level of satisfaction with on-demand transport came when participants were presented with the option of a "luxury" shared on-demand ridehailing service, represented by MOIA's specialized vehicles built for the express purpose of dynamic ridepooling. The expectations of the researchers were that the luxury service would be appealing to both categories of focus groups, since it gave a much higher level of service than either group currently had access to.

The Potential Users were considerably more interested and positive in their response to the luxury vans; once given a concrete example of what a public transport service could be like, they were much more interested and willing to try a shared, public transport product after watching the MOIA video.

However, the Experienced Users did not find MOIA a particularly compelling offer. Their satisfaction and loyalty to the existing service derived from their perception that the drivers, vehicles, as well as other riders offered a consistent and shared experience. The interpretation is that the elements created a kind of community or herd behaviour, as well as engendering greater trust in authority; in this case, the authority of the public transport agency, as commercial ridehailing services were not seen as delivering on a consistent or satisfactory level. 
The overall satisfaction of travellers, and the likelihood of continuing to use a shared transport service, appeared to be impacted by variations in the social aspect of sharing and their exposure to public transport services or confidence in the public transport authority. This might be evidence for introducing shared, on-demand transport into smaller, less diverse communities - counter to how on-demand ridehailing has been offered in new territories previously - as the higher levels of community can offer a consistent expectation of the service in users, higher confidence in word-of-mouth, and a stronger likelihood of habit creation.

\subsection{Sharing Anxiety Grows in an Authority Vacuum}

Both commercial and public transport entities that are actively developing SAV offers try to capitalize on the familiarity of existing services and customers. However, when both Potential and Experienced Users were presented with the possibility of using a driverless, shared, on-demand service, their willingness dropped significantly-even if they had been previously enthusiastic proponents of dynamic ridepooling. Where other studies interpreted this as a fear of the navigation technology, our results revealed that the concern was not primarily the loss of the driver as responsible for manoeuvring the vehicle, but that the driver represented an authority figure to riders.

This was evident when Experienced Users spoke warmly and affectionately about the drivers, mentioning the personal attention and high quality service that they had received. The human element could be seen as a motivator for the high levels of satisfaction they expressed in the service, so much so that the vehicles used did not impact them as much, and the potential "luxury van" offer did not motivate these participants. However, when the driver was removed, their willingness to use the service dropped significantly. This indicates that the trust in authority, a valuable factor in the satisfaction with the current on-demand public transport service offer, was lost when the vehicle was driverless.

Conversely, Potential Users had extremely low opinions of drivers due to the times that drivers failed to be responsible for their well-being and safety. Participants (especially women) discussed how the presence of a driver could either make them feel less or more safe, depending on the behaviour of the driver as well as other riders. Further, in relation to having that sense of community, public transportation was noted to be generally safer, since it offered a collective responsibility for people to look out for one another, especially in times of crisis, as well as more authority figures.

All groups emphasized that there is a need to know "who is in control" - not of, but within the vehicle. Many questions arose in the discussions about dangerous scenarios and the users' uncertainty about their obligation to react-or indeed, who held that obligation at all. This indicates that extensive and transparent information on safety protocols in any future service would be needed to alleviate sharing anxiety in driverless SAVs.

Although concerns and fears about AVs have been noted in previous studies [25,33,41,42], most of this work was conducted in the context of technological acceptance, with many of the questions focusing on the technological aspects of vehicular safety, programming, function, and logic. Perhaps because people are already consuming shared mobility as a product (in the form of ridehailing and dynamic ridepooling) there is an implicit assumption in the research sphere that the acceptance of autonomous mobility, particularly SAVs, is a problem of technological acceptance. However, these focus groups demonstrated that this may not be the case. (As the COVID-19 situation has shown, there will also be increased concerns regarding sharing spaces with unknown persons for the foreseeable future.) Rather, we may need to look at introducing new mobility advances as a sociotechnical transition, one that can be designed, planned, and orchestrated by stakeholders.

\subsection{Implications}

The results of the focus groups suggested some motivating and some hindering factors for user willingness-to-share mobility journeys, especially for autonomous or driverless ridepooling. Similar to Herzberg's Motivation Theory [43], some of the factors that emerged, 
like safety, could be considered 'hygiene factors' (as in, without their presence, the user will not take action), while cost, comfort, and convenience would be seen as 'motivating factors'. This means there are minimum thresholds of attractiveness that must be met in order for someone to consider using shared mobility.

With Herzberg's Motivation Theory as inspiration, we attempted to synthesize the results from the focus groups and the flow of the willingness-to-use into willingness-toshare by developing the following model. We break the model down into three stages for explanation here, beginning with Figure 1 below.

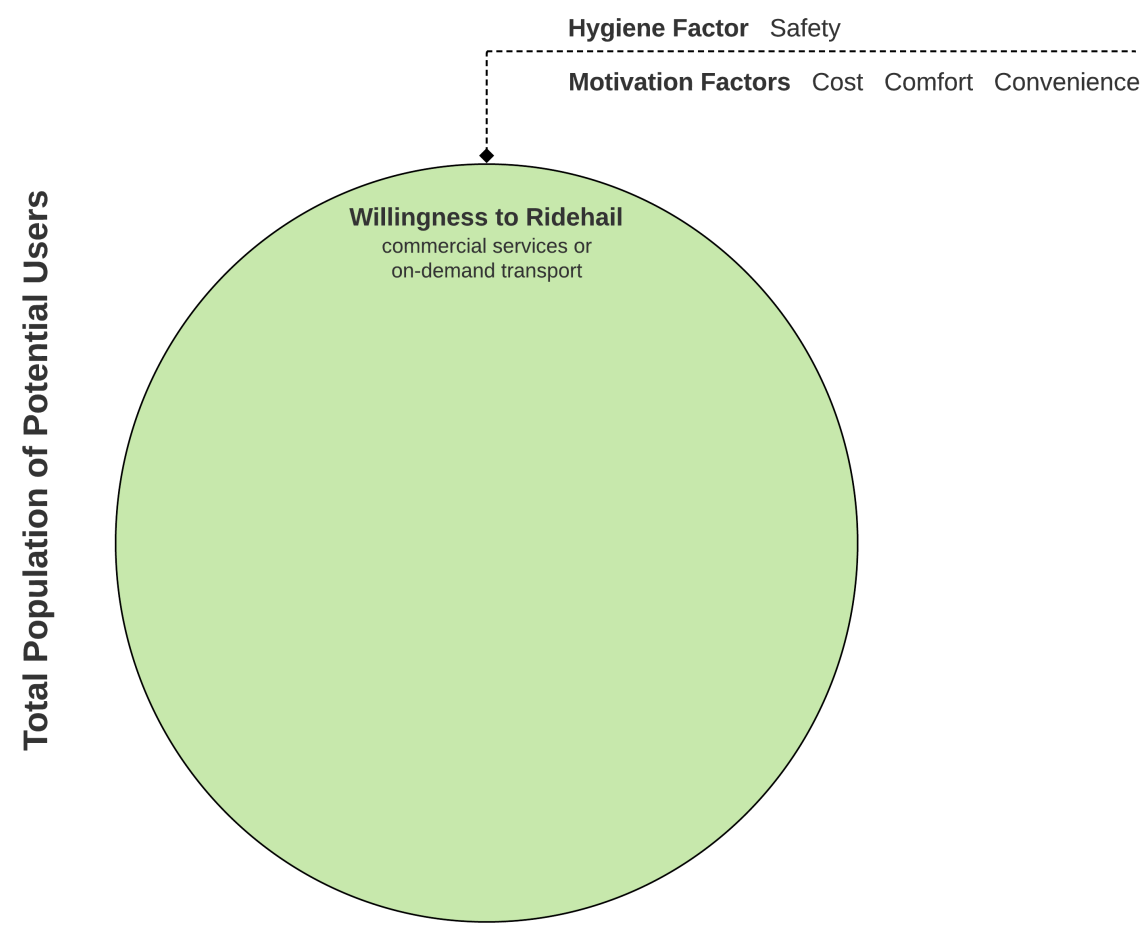

Figure 1. The first stage of the Willingness-to-Share-Autonomous vehicles (AVs) Model. Within the total population of potential users of mobility services, there is a subset that is willing to use ridehailing services. For these users, the hygiene factor of safety is met, as are the conditions of cost, comfort, and convenience. If these conditions are not met, then the potential users are not willing to use ridehailing services.

The first stage represents the total population of all potential users (the white background), and within that, a group of people who would demonstrate a willingness-to-use ridehailing services (the green circle). Within the group of people who are willing-to-use ridehailing or on-demand services, there may also be users who are comfortable with sharing their space, ride prioritization, trust the service operator, and feel a sense of community or familiarity with other riders and the service. If these factors are not true for a user, then their needs are unmet, and they may drop out of ridehailing services altogether or continue to use them but only in a private (unshared ride) context. If these factors are true, then this group of people may also be willing-to-share dynamic ridepooled services or shared, on-demand transport (see Figure 2). 


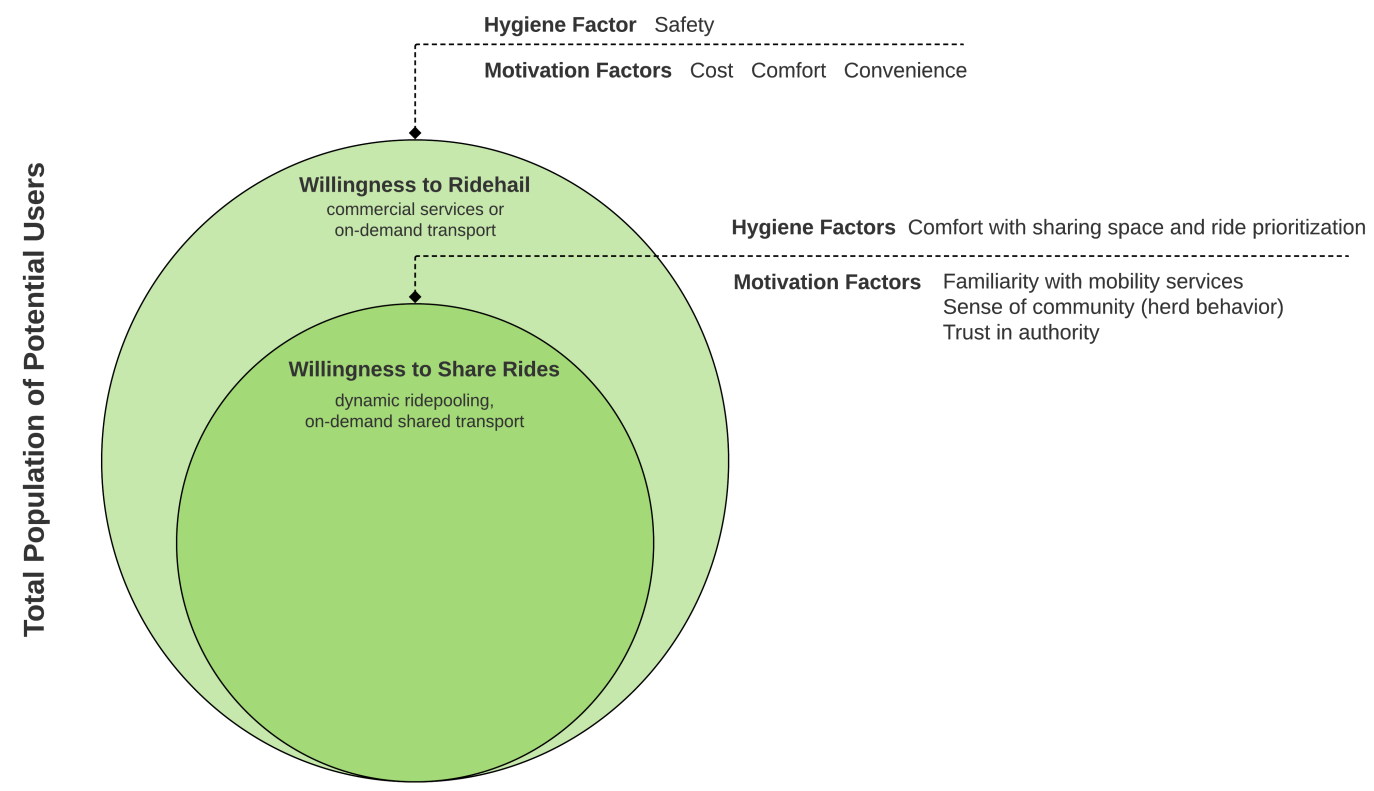

Figure 2. Second stage of the Willingness-to-Share-AVs Model, where users decide between private-unshared rides or dynamic ridepooling.

In our focus groups, it became evident that, even for highly motivated users, when faced with the hypothetical of a driverless vehicle (specifically the removal of the presence of the driver), their willingness-to-share was not the same. Removing the driver removed an important element for them; essentially, their sense of control within the vehicle. The presence of a driver is taken for granted or as an assumption by users. They are not aware of the driver's presence (and subsequent importance) to their decision making or comfort, until explicitly presented with the possibility of its absence; see Figure 3.

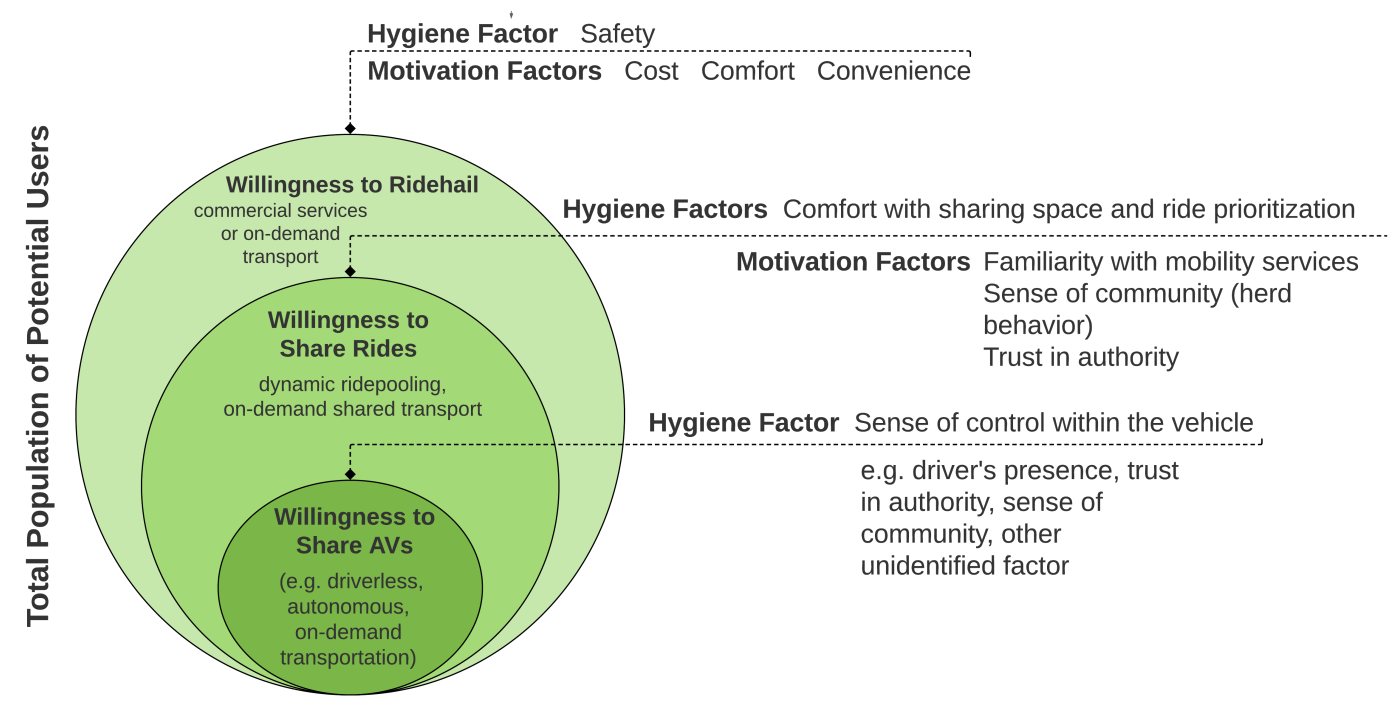

Figure 3. Third stage and complete view of the Willingness-to-Share-AVs Model, which indicates a smaller segment of the population who believes that they are motivated to use driverless commercial dynamic ridepooling and autonomous on-demand transport.

This indicates that the driver's presence represents something valuable to persons using on-demand, shared transport and that other factors need to be identified, explored, and strengthened if they are to increase the willingness-to-share and overcome the dampening effect of sharing anxiety that can be present in the absence of a driver. 
The type of mobility service being examined here is the combination of several elements: on-demand, dynamic (i.e., not a fixed route), shared (pooled), and eventually, driverless. While the technological acceptance of on-demand and dynamic was quickly embraced by the general public (evidenced by the proliferation of on-demand ridehailing globally), the social acceptance of shared rides is less understood; and what both shared and driverless experiences might mean to future users is still an unknown context.

However, many cities, municipalities, regional governments, and nations the world over are already making significant investments into competing in the autonomous vehicle domain, either in supporting the local industry in its production or in attempting to "futureproof" their competitiveness by making their urban and economic conditions conducive to its adoption. Therefore, this research area is crucial to meet the challenges of the social transition proactively, contributing to the development of autonomous mobility offers for the future.

\section{Summary \& Conclusions}

The aim of this study was to examine the factors impacting people's willingness-toshare for mobility journeys and trips, particularly in a shared autonomous public transport context. This study employed a qualitative approach to address the following questions:

- What factors (if any), beyond socio-economic factors, impact travellers' willingnessto-share on-demand services?

- What factors impact the willingness-to-share on-demand public transport?

- Are these the same factors or different ones?

The participants discussed at length what motivated them to partake in commercial ridehailing services as well as on-demand transport services. Several themes emerged across all of the focus groups, independent of the type of service discussed: cost, comfort, convenience, and safety. These are all factors that have been previously confirmed in other work.

- If the on-demand public transport vehicle is a shared $\mathrm{AV}$, does the willingness-to-share the service of travellers change?

However, our study revealed an additional, demotivating factor, something that reduced the willingness-to-share in the context of shared, driverless vehicles: we call this 'sharing anxiety'. Sharing anxiety, particularly in the context of driverless vehicles, mainly stemmed from the concerns of potential riders about joining their mobility trip in the same vehicle with strangers while having no authority figure present.

TfNSW is preparing for shared, autonomous public transport; however, since technology of that capacity is not yet available, introducing on-demand public transport, with drivers, appears to have had a positive impact in normalizing several aspects of future mobility services that are prerequisites for creating and promoting safe, shared, autonomous public transport. One proposal would be that public transit agencies and operators introduce on-demand public transport products for a significant period of time before introducing shared autonomous public transport to their communities.

This is because addressing sharing anxiety should be considered critical for the proliferation of sustainable and increasingly digitized, on-demand public transport, and it could potentially be mitigated by introducing on-demand transport or commercial ridehailing into regions to create bridging acceptance or behaviours in the public.

Significant future work in understanding sharing anxiety and authority vacuums in driverless spaces is needed in order to create valid transition strategies for autonomous public transportation.

Author Contributions: Conceptualization, S.D. and M.K.; methodology, M.K. and H.S.; software, S.D.; validation, H.S., Y.Z.W., and M.K.; formal analysis, S.D.; investigation, S.D. and Y.Z.W.; resources, M.K.; data curation, S.D.; writing—original draft preparation, S.D.; writing—review and editing, H.S., Y.Z.W., and M.K.; visualization, S.D.; supervision, M.K.; project administration, S.D.; funding acquisition, S.D. All authors have read and agreed to the published version of the manuscript. 
Funding: This research was funded by Vinnova, the Swedish innovation agency, grant number 2018-04063. The research team was also provided a grant by Transport for New South Wales to University of Sydney Business School, without which the work would not have been possible.

Institutional Review Board Statement: The study was conducted according to the guidelines of the Central Ethics Review Board of Sweden.

Informed Consent Statement: All subjects gave their informed consent for inclusion before they participated in the study. The study was conducted in accordance with the Declaration of Helsinki.

Data Availability Statement: The data presented in this study is available in anonymized format on request from the corresponding author. The data is not publicly available due to privacy concerns.

Acknowledgments: The first author would like to deeply thank the University of Sydney's Institute for Transport and Logistics's David Hensher, John Nelson, and Yale Wong for hosting and supporting the research visit; this work would not have been possible without their drive, expertise, and optimism. We also thank Virginie Vernin at Transport for New South Wales and Sue Wiblin at KeolisDowner for helping to translate this work to stakeholders and a broader audience. Sincere thanks to Jillian Fernandez for feedback and moral support.

Conflicts of Interest: Vinnova had no role in the design of the study; in the collection, analyses, or interpretation of data; in the writing of the manuscript, or in the decision to publish the results. Transport for New South Wales assisted the first author in networking with regional transport operators and coordinated with University of Sydney Business School, but had no role in the analyses, interpretation, writing of the manuscript, or the decision to publish.

\section{Abbreviations}

The following abbreviations are used in this manuscript:

AVs Autonomous vehicles

ODT on-demand transport

TfNSW Transport for New South Wales

SAVs shared autonomous vehicles

QDAS qualitative data analysis software

\section{Appendix A}

Video files of the grounding mediums used during the focus group, for reference.

\section{Appendix B}

Appendix B.1. Inner West

The Inner West is not an officially designated geographical region; the Australian Government Bureau of Statistics, the New South Wales Government Department of Planning and Infrastructure, and local media variously describe the Inner West region to include six local government areas: Burwood, Canada Bay, Inner West Council, Strathfield, Canterbury-Bankstown, and the western side of City of Sydney. However, although there is not a single cohesive governing body for this area, the Australian Government Bureau of Statistics does keep statistics on the region. There are approximately 319,000 persons living in the Inner West suburbs and neighbourhoods of Sydney, with a significantly dense public transit offer and high walkability.

The average monthly income of the area is $\$ 7740$ AUD. There are 19 bus lines servicing a region of Sydney, four train lines, 11 stations, and two ferries, and approximately 5000 inhabitants per square km. Many important sites are found within Inner West, such as Darling Harbor, the University of Sydney, and Australian Catholic University. There is a significant amount of diversity in the area, represented by enclaves in particular neighbourhoods, which have developed a reputation for a type of cuisine (i.e., Chatswood as an Asian centre), or celebrations of diversity and tolerance (i.e., LGBQTA-establishments in Newtown) and supplemented by a large student population with significant numbers from international countries. 


\section{Appendix B.2. Macquarie Park}

The community of Macquarie Park used to be part of a larger zipcode known as North Ryde before being established as its own area in 1999 and is home to approximately 8000 persons with a population density of around 1,100 persons per square kilometer. The average monthly income is $\$ 6580$ AUD. During the 1970s, several large companies located their corporate headquarters in the area, and, over the decades, it gained a reputation of being a leading high-tech industrial area, home to numerous international companies, such as AstraZeneca, Ford Motor Co, Johnson \& Johnson, Novartis, and Oracle. The region of both Macquarie Park and North Ryde provides approximately 92,000 jobs despite only having 57,000 residents.

Macquarie Park has access to the M2 Hills Motorway, that runs through the northern part of the suburb but has a reputation for becoming extremely congested during commuting and peak times. Three metro stations, Macquarie Park, Macquarie University, and North Ryde opened on 26 May 2019. Approximately 30\% of census takers in Macquarie Park reported driving to work, significantly lower than the New South Wales or national averages of $57.8 \%$ of $61.5 \%$, respectively.

\section{Appendix B.3. Northern Beaches}

The region known as the Northern Beaches is located in northern Sydney on a 40-km coastline stretch within three local councils, including Manly, Warringah, and Pittwater, with a population of about 252,878 in 2016; there is much lower population density in the Northern Beaches since the typical form of housing is larger single family dwellings, as opposed to the row houses or apartments in downtown Sydney. Its proximity to the beach typically means higher real estate values; the average monthly income in the area is approximately $\$ 8712$ AUD. On the day of the last census, $60.3 \%$ of employed persons reported using a car (either as driver or as passenger) as their primary form of commute, and the Northern Beaches Council provide parking permit stickers that give free parking at more than 40 Northern Beaches locations.

The main form of public transport are buses, which connect to the main train stations at Chatswood, North Sydney and the city, as well as the ferry wharf at Manly. The main bus interchanges are at Pittwater Road at Brookvale, Dee Why, Mona Vale, and Manly Wharf. The NSW Government identified the Northern Beaches as an area that would benefit from feeder services to public transport, which included the introduction of the B-Line express bus from Newport to the Sydney Central Business District. Keoride's first pilot was introduced in the Northern Beaches in an attempt to pool rides on-demand and deliver residents to areas within the Northern Beaches, including the Mona Vale terminus for the B-Line.

\section{Appendix B.4. Newcastle}

Newcastle is located approximately two hours north of Sydney; it is the second largest metropolitan zone in the state of New South Wales. Beginning in the 1870s, the region developed heavily in the mining and production industries of coal, copper, and steel. While those industries suffered a major decline in the 1970s, a small resurgence in the late 2000s allowed the region to weather the "Great Recession" slightly better than other parts of New South Wales. However, the largest employers today are the Hunter New England Regional Health Service and University of Newcastle. This is New South Wales' second-largest city with a population of 152,948 in 2016; the average monthly income is \$7396 AUD.

On the day of the census, $73.5 \%$ of employed respondents reported using a car (either as driver or as passenger) to commute; to ease the commute of its residents, the City of Newcastle expanded its light rail network and created a new transport interchange in key destinations. Newcastle Shuttle Bus services were also introduced to replace train services between Hamilton and Newcastle stations. The transport operator KeolisDowner also operated an on-demand transport service called Newcastle On-Demand (using the same technology as Keoride in Northern Beaches and Macquarie Park but with a differently 
branded app and interface). At the time of the study, an AV shuttle pilot had been delayed, and its three-month trial was implemented in July of 2020.

\section{References}

1. Haboucha, C.J.; Ishaq, R.; Shiftan, Y. User preferences regarding autonomous vehicles. Transp. Res. Part C Emerg. Technol. 2017, 78, 37-49 [CrossRef]

2. Schwarting, W.; Alonso-Mora, J.; Rus, D. Planning and decision-making for autonomous vehicles. Annu. Rev. Control. Robot. Auton. Syst. 2018, 1, 187-210. [CrossRef]

3. Becker, F;; Axhausen, K.W. Literature review on surveys investigating the acceptance of automated vehicles. Transportation 2017, 44, 1293-1306. [CrossRef]

4. Dias, F.F.; Lavieri, P.S.; Garikapati, V.M.; Astroza, S.; Pendyala, R.M.; Bhat, C.R. A behavioral choice model of the use of car-sharing and ride-sourcing services. Transportation 2017, 44, 1307-1323 [CrossRef]

5. Sperling, D.; Pike, S.; Chase, R. Will the Transportation Revolutions Improve Our Lives-Or Make Them Worse? In Three Revolutions; Island Press: Washington, DC, USA, 2018; pp. 1-20.

6. Pakusch, C.; Stevens, G.; Bossauer, P. Shared Autonomous Vehicles: Potentials for a Sustainable Mobility and Risks of Unintended Effects. 2018; pp. 258-269. Available online: https://wwww.easychair.org/publications/download/6LTq (accessed on 20 October 2019).

7. OECD; ITF; CPB. How Shared Self-Driving Cars Could Change City Traffic (Corporate Partnership Board Report). Urban Mobility System Upgrade. 2015. Available online: http:/ /www.itfoecd.org/sites/default/files/docs/15cpb_self-drivingcars.pdf (accessed on 27 November 2019).

8. Wang, Y.; Wang, S.; Wang, J.; Wei, J.; Wang, C. An empirical study of consumers' intention to use ride-sharing services: Using an extended technology acceptance model. Transportation 2018, 47, 397-415. [CrossRef]

9. Gurumurthy, K.M.; Kockelman, K.M.; Simoni, M.D. Benefits and costs of ride-sharing in shared automated vehicles across Austin, Texas: Opportunities for congestion pricing. Transp. Res. Rec. 2019, 2673, 548-556. [CrossRef]

10. Zhang, W.; Guhathakurta, S.; Fang, J.; Zhang, G. Exploring the impact of shared autonomous vehicles on urban parking demand: An agent-based simulation approach. Sustain. Cities Soc. 2015, 19, 34-45. [CrossRef]

11. Fraedrich, E.; Heinrichs, D.; Bahamonde-Birke, F.J.; Cyganski, R. Autonomous driving, the built environment and policy implications. Transp. Res. Part A Policy Pract. 2019, 122, 162-172. [CrossRef]

12. Clewlow, R.R.; Mishra, G.S. Disruptive Transportation: The Adoption, Utilization, and Impacts of Ride-Hailing in the United States. Institute of Transportation Studies, University of California; Research Report UCD-ITS-RR-17-07. 2017. Available online: https: / / escholarship.org/uc/item/82w2z91j (accessed on 1 May 2021).

13. Wong, Y.Z.; Hensher, D.A.; Mulley, C. Mobility as a service (MaaS): Charting a future context. Transp. Res. Part A Policy Pract. 2020, 131, 5-19. [CrossRef]

14. Hall, J.D.; Palsson, C.; Price, J. Is Uber a substitute or complement for public transit? J. Urban Econ. 2018, 108, 36-50. [CrossRef]

15. Merat, N.; Madigan, R.; Nordhoff, S. Human Factors, User Requirements, and User Acceptance of Ride-Sharing in Automated Vehicles. In International Transport Forum Discussion Papers, No. 2017/10; OECD Publishing: Paris, France, 2017. [CrossRef]

16. Greenblatt, J.B.; Shaheen, S. Automated vehicles, on-demand mobility, and environmental impacts. Curr. Sustain. Renew. Energy Rep. 2015, 2, 74-81 [CrossRef]

17. Chavis, C.; Gayah, V.V. Development of a mode choice model for general purpose flexible-route transit systems. Transp. Res. Rec. 2017, 2650, 133-141. [CrossRef]

18. Lavieri, P.S.; Bhat, C.R. Investigating objective and subjective factors influencing the adoption, frequency, and characteristics of ridehailing trips. Transp. Res. Part C Emerg. Technol. 2019, 105, 100-125. [CrossRef]

19. Smith, A. On-Demand: Ridehailing Apps. Online Press of Pew Research Center. Available online: http://www.pewinternet.org/ 2016/05/19/on-demand-ridehailing-apps/ (accessed on 29 August 2016).

20. Buliung, R.N.; Soltys, K.; Habel, C.; Lanyon, R. Driving factors behind successful carpool formation and use. Transp. Res. Rec. 2009, 2118, 31-38. [CrossRef]

21. Delhomme, P.; Gheorghiu, A. Comparing French carpoolers and non-carpoolers: Which factors contribute the most to carpooling? Transp. Res. Part D Transp. Environ. 2016, 42, 1-15. [CrossRef]

22. Chen, X.M.; Zahiri, M.; Zhang, S. Understanding ridesplitting behavior of on-demand ride services: An ensemble learning approach. Transp. Res. Part C Emerg. Technol. 2017, 76, 51-70. [CrossRef]

23. Malodia, S.; Singla, H. A study of carpooling behaviour using a stated preference web survey in selected cities of India. Transp. Plan. Technol. 2016, 39, 538-550. [CrossRef]

24. Tahmasseby, S.; Kattan, L.; Barbour, B. Propensity to participate in a peer-to-peer social-network-based carpooling system. J. Adv. Transp. 2016, 50, 240-254. [CrossRef]

25. Sarriera, J.M.; Álvarez, G.E.; Blynn, K.; Alesbury, A.; Scully, T.; Zhao, J. To share or not to share: Investigating the social aspects of dynamic ridesharing. Transp. Res. Rec. 2017, 2605, 109-117. [CrossRef]

26. Amirkiaee, S.Y.; Evangelopoulos, N. Why do people rideshare? An experimental study. Transp. Res. Part F Traffic Psychol. Behav. 2018, 55, 9-24. [CrossRef] 
27. Wicki, M.; Fesenfeld, L.; Bernauer, T. In search of politically feasible policy-packages for sustainable passenger transport: Insights from choice experiments in China, Germany, and the USA. Environ. Res. Lett. 2019, 14, 084048. [CrossRef]

28. Tennant, C.; Howard, S.; Franks, B.; Bauer, M.; Stares, S.; Pansegrau, P.; Stysko-Kunkowska, M.; Cuevas-Badallo, A. Autonomous Vehicles-Negotiating a Place on the Road: A Study on How Drivers Feel about Interacting with Autonomous Vehicles on the Road; London School of Economics and Political Science: London, UK, 2017.

29. Golbaebi, G. Individual predictors of autonomous vehicle public acceptance and intention to use: A systematic review of the literature. J Open Innov. Technol. Mark. Complex. 2020, 6, 106. [CrossRef]

30. Madigan, R.; Louw, T.; Wilbrink, M.; Schieben, A.; Merat, N. What influences the decision to use automated public transport? Using UTAUT to understand public acceptance of automated road transport systems. Transp. Res. part F Traffic Psychol. Behav. 2017, 50, 55-64. [CrossRef]

31. Addison Lee Ltd. MERGE Greenwich: The MERGE Greenwich Project. Connected and Autonomous Vehicle Research and Development Projects, September 2018; p. 33. Available online: https://assets.publishing.service.gov.uk/government/uploads/ system/uploads/attachment_data/file/737778/ccav-research-and-development-projects.pdf (accessed on 8 May 2019).

32. Barbour, N.; Menon, N.; Zhang, Y.; Mannering, F. Shared automated vehicles: A statistical analysis of consumer use likelihoods and concerns. Transp. Policy 2019, 80, 86-93. [CrossRef]

33. Sanguinetti, A.; Kurani, K.; Ferguson, B. Is It OK to Get in a Car with a Stranger? Risks and Benefits of Ride-pooling in Shared Automated Vehicles. UC Office of the President: University of California Institute of Transportation Studies. 2019. Available online: https: / / escholarship.org/uc/item/1cb6n6r9 (accessed on 1 May 2019).

34. Nelson, J.D.; Wright, S. Flexible Transport Services. In Handbook of Public Transport; Mulley, C., Nelson, J.D., Ison, S., Eds.; Routledge: Abingdon, UK, 2021.

35. Neoh, J.G.; Chipulu, M.; Marshall, A. What encourages people to carpool? An evaluation of factors with meta-analysis. Transportation 2017, 44, 423-447. [CrossRef]

36. Dedema, Z.P. Happy Rides Are All Alike; Every Unhappy Ride Is Unhappy in Its Own Way": Passengers' Emotional Experiences While Using a Mobile Application for Ride-Sharing. In Information in Contemporary Society. iConference 2019. Lecture Notes in Computer Science; Taylor, N., Christian-Lamb, C., Martin, M., Nardi, B., Eds.; Springer: Cham, Switzerland, 2019; Volume 11420, pp. 706-717

37. Krueger, R.A.; Casey, M.A. Designing and Conducting Focus Group Interviews; The Social Development Family of the World Bank: Washington, DC, USA, 2001. Available online: https:/ / citeseerx.ist.psu.edu/viewdoc/download?doi=10.1.1.607.4701\&rep=rep1 \&type $=$ pdf (accessed on 1 May 2019).

38. Ho, L.; Mulley, C.; Lin, H.; Royle, D. How do you tell if a regional area may support an on-demand service? In Proceedings of the 16th International Conference on Competition and Ownership in Land Passenger Transport (Thredbo 16), Singapore, 25-29 August 2019.

39. Merton, R.K.; Fiske, M.; Kendall, P.L. The Focused Interview: A Manual of Problems and Procedures, 2nd ed.; Free Press: New York, NY, USA, 1990.

40. Quarles, N.T.; Kockelman, K.M. Americans' Plans for Acquiring and Using Electric, Shared and Self-Driving Vehicles. In Proceedings of the 99th Annual Meeting of the Transportation Research Board, Washington, DC, USA, 23 January 2020.

41. Zhao, J. Humanizing Travel: Investigating the User Identification of, Attitude towards and Preference for Dynamic Ridesharing Services (No. MITR25-18); New England University Transportation Center, Massachussetts Institute of Technology: Cambridge, MA, USA, 2017.

42. Aarhaug, J. Implications of ride-sourcing and self-driving vehicles on the need for regulation in unscheduled passenger transport. Res. Transp. Econ. 2018, 69, 573-582. [CrossRef]

43. Herzberg, F. Motivation-hygiene theory. In Organizational Behavior One: Essential Theories of Motivation and Leadership; Miner, J.B., Ed.; ME Sharpe Inc.: New York, NY, USA, 2005; pp. 61-74. 